Research Paper

\title{
Piperlongumine potentiates the effects of gemcitabine in in vitro and in vivo human pancreatic cancer models
}

\author{
Jiyan Mohammad ${ }^{1}$, Harsharan Dhillon ${ }^{1}$, Shireen Chikara ${ }^{1}$, Sujan Mamidi ${ }^{2}$, Avinash \\ Sreedasyam², Kishore Chittem ${ }^{3}$, Megan Orr ${ }^{4}$, John C. Wilkinson ${ }^{5}$ and Katie M. \\ Reind ${ }^{1}$ \\ ${ }^{1}$ Department of Biological Sciences, North Dakota State University, Fargo, ND 51808, USA \\ ${ }^{2}$ Genome Sequencing Center, HudsonAlpha Institute for Biotechnology, Huntsville, AL 35806, USA \\ ${ }^{3}$ Department of Plant Pathology, North Dakota State University, Fargo, ND 51808, USA \\ ${ }^{4}$ Department of Statistics, North Dakota State University, Fargo, ND 51808, USA \\ ${ }^{5}$ Department of Chemistry and Biochemistry, North Dakota State University, Fargo, ND 51808, USA \\ Correspondence to: Katie M. Reindl, email: katie.reindl@ndsu.edu \\ Keywords: apoptosis; cell cycle regulation; complementary and alternative therapy; reactive oxygen species; RNA-Seq \\ Received: September 13,2017 Accepted: December 15, $2017 \quad$ Published: December 23, 2017 \\ Copyright: Mohammad et al. This is an open-access article distributed under the terms of the Creative Commons Attribution \\ License 3.0 (CC BY 3.0), which permits unrestricted use, distribution, and reproduction in any medium, provided the original author \\ and source are credited.
}

\section{ABSTRACT}

Pancreatic ductal adenocarcinoma (PDAC) is one of the deadliest cancers due to a late diagnosis and poor response to available treatments. There is a need to identify complementary treatment strategies that will enhance the efficacy and reduce the toxicity of currently used therapeutic approaches. We investigated the ability of a known ROS inducer, piperlongumine (PL), to complement the modest anti-cancer effects of the approved chemotherapeutic agent gemcitabine (GEM) in PDAC cells in vitro and in vivo. PDAC cells treated with PL + GEM showed reduced cell viability, clonogenic survival, and growth on Matrigel compared to control and individually-treated cells. Nude mice bearing orthotopically implanted MIA PaCa-2 cells treated with both PL $(5 \mathrm{mg} / \mathrm{kg})$ and GEM $(25 \mathrm{mg} / \mathrm{kg})$ had significantly lower tumor weight and volume compared to control and single agent-treated mice. RNA sequencing (RNA-Seq) revealed that PL + GEM resulted in significant changes in p53-responsive genes that play a role in cell death, cell cycle, oxidative stress, and DNA repair pathways. Cell culture assays confirmed PL + GEM results in elevated ROS levels, arrests the cell cycle in the G0/G1 phase, and induces PDAC cell death. We propose a mechanism for the complementary anti-tumor effects of PL and GEM in PDAC cells through elevation of ROS and transcription of cell cycle arrest and cell death-associated genes. Collectively, our results suggest that PL has potential to be combined with GEM to more effectively treat PDAC.

\section{INTRODUCTION}

Pancreatic ductal adenocarcinoma (PDAC) is the third most common cause of cancer death in the United States with a 5 -year relative survival rate of only $8 \%$ [1]. Though surgery is the most effective treatment for PDAC, the majority of pancreatic tumors are not surgically resectable. A standard treatment approach for non-resectable pancreatic tumors is the use of chemotherapeutic agents that are toxic to cancer cells as well as healthy cells.

Gemcitabine (GEM), a cytidine analog that inhibits DNA synthesis and DNA repair, is currently a drug of choice for treating PDAC [2]. However, treatment with GEM leads to only a modest improvement in overall survival of PDAC patients [3]. To increase GEM's 
efficacy, adjuvant therapies such as 5-fluorouracil, nabpaclitaxel, or cisplatin are often used [4]. These agents target other mechanisms used by cancer cells to grow and divide. However, these approaches have had limited success, and only extend life span by a few months with additional toxicity [5-7]. Therefore, there is a need for complementary approaches that effectively inhibit tumor progression without introducing more toxicity to healthy cells.

Piperlongumine (PL) is a bioactive agent derived from the fruits and roots of the long pepper plant. PL has been shown to kill numerous cancer cell types without affecting normal cells $[8,9]$. We have previously shown that PL inhibits PDAC cell proliferation in vitro and in vivo by enhancing ROS and DNA damage [10]. Further, we have identified that oxidative stress and endoplasmic reticulum stress-associated genes are significantly altered in PDAC cells upon PL treatment [11]. We postulate that using PL in combination with GEM will enhance PDAC cell death by raising ROS to a level that induces cell death. The rationale for this therapeutic approach is that highly metabolic tumor cells have heightened basal oxidative stress and are susceptible to cell death when additional oxidative stress is induced [12]. Here, we demonstrate the ability of PL to enhance the effects of GEM for PDAC treatment. Further, we identified the underlying mechanisms for the enhanced anti-tumor effects of PL + GEM in PDAC cells which include elevation of ROS and differential expression genes including cell cycle and apoptosis-associated genes.

\section{RESULTS}

\section{PL enhances the effects of GEM on PDAC cell viability in vitro}

The combination of GEM with additional agents has shown modest survival benefits for PDAC patients compared to single-agent gemcitabine [5-7]. To determine if PL could enhance the effects of GEM on the viability of PDAC cells, we conducted MTT assays in both MIA PaCa-2 and PANC-1 cells. These two cell lines are both derived from poorly differentiated primary tumors and exhibit KRAS and TP53 mutations, and homozygous deletion of p16 [17]. However, PANC-1 cells are much more resistant to GEM than MIA $\mathrm{PaCa}-2$ cells and represent a nice model to identify agents that might potentiate the effects of GEM [18]. The concentrations of PL and GEM were optimized for the MTT and other cell-based experiments (data not shown). Cells were then treated with PL $(1$ or $2 \mu \mathrm{M}), \operatorname{GEM}(1,10$, or 100 $\mathrm{nM}$ ), or their combinations for $72 \mathrm{~h}$. Cell viability was significantly reduced in PL + GEM-treated MIA PaCa-2 and PANC-1 cells compared to vehicle-treated controls and single agent-treated cells (Figure 1A and 1B). Based on Jin's formula [19], $1 \mu \mathrm{M}$ PL + 100 nM GEM, $2 \mu \mathrm{M}+$
$10 \mu \mathrm{M}$ GEM, and $2 \mu \mathrm{M}$ PL $+100 \mathrm{nM}$ GEM had additive effects for MIA PaCa- 2 cells. However, $1 \mu \mathrm{M}$ PL $+1 \mathrm{nM}$ GEM and $2 \mu \mathrm{M}$ PL $+1 \mathrm{nM}$ GEM had synergistic effects for these same cells. In PANC-1 cells, PL + GEM had synergistic effects for all combinations except $1 \mu \mathrm{M}$ PL +10 nM GEM which had an antagonistic effect for both cell lines. Similar to findings in literature, we noted MIA $\mathrm{PaCa}-2$ cells were more sensitive than PANC-1 cells to GEM; therefore, the ability of PL to enhance GEM's antiproliferative effects were more apparent in PANC1 cells than MIA PaCa-2 in this particular assay (Figure $1 \mathrm{~A}$ and 1B). In general, the combination of PL + GEM showed a modest, but statistically significant, inhibition of PDAC cell viability than either treatment alone during this short-term assay.

\section{PL in combination with GEM reduces PDAC cell clonogenic survival}

A longer-term assay (clonogenic survival) was employed to determine the ability of PL in combination with GEM to influence PDAC cell survival. MIA PaCa2 and PANC-1 cells were treated with GEM (1 nM), PL $(1 \mu \mathrm{M})$, or GEM $(1 \mathrm{nM})+$ PL $(1 \mu \mathrm{M})$, for 10 days after which the number of colonies formed was counted (Figure 1C). PL in combination with GEM significantly reduced the number of colonies (surviving fraction) compared to control and GEM for both cell lines (Figure 1D). In addition to a reduction in the number of colonies, the colony size appears to be smaller in the PL + GEM treatment (Figure 1C), suggesting that the combination also prevents clonogenic expansion of existing tumor cells.

\section{PL in combination with GEM reduces PDAC cell growth on Matrigel}

To evaluate the effect of PL in combination with GEM in a more physiologically relevant culture system, we used a Matrigel growth assay. Matrigel is an extracellular matrix consisting of collagen, laminin, and proteoglycans that is extracted from a mouse sarcoma and used to mimic the extracellular environment a tumor cell encounters. PDAC cells, MIA PaCa-2 and PANC-1, were treated with PL $(1 \mu \mathrm{M})$ or GEM $(1 \mu \mathrm{M})$ alone or PL $(1 \mu \mathrm{M})+\mathrm{GEM}$ $(1 \mu \mathrm{M})$, for 4 days. GEM alone was much less effective at reducing PDAC cell growth on Matrigel ( $\mu \mathrm{M}$ range; Figure 1E) compared to traditional 2-D cultures (nM range; Figure 1A-1C), whereas PL showed a similar capacity to inhibit PDAC cell growth in the various growth environments. It was interesting to note a remarkable enhancement of the combination treatment in the growth-stressed Matrigel culture model compared to traditional culture model where the images clearly show that PL + GEM reduced both MIA PaCa-2 and PANC-1 cell growth as compared to control or single-agent treatments (Figure 1E). Therefore, 
the combination of PL + GEM allowed for significantly improved growth inhibition over single-agent GEM in the Matrigel assay. This is likely because PL works equally well in both growth environments, whereas GEM does not.

\section{PL enhances the in vivo therapeutic effects of GEM in an orthotopic mouse model}

The promising results obtained from the Matrigel in vitro model evaluating PL + GEM prompted us to further explore this drug combination in an orthotopic animal model of PDAC. We evaluated the therapeutic advantage of combining PL + GEM in nude mice bearing orthotopically implanted MIA PaCa-2 cells. Doses of $5 \mathrm{mg} / \mathrm{kg}$ of PL and $25 \mathrm{mg} / \mathrm{kg}$ GEM were selected for intraperitoneal administration three times a week (Figure 2A) based on previously published reports [23-25]. The treatment efficacy was determined by considering the mean pancreatic tumor weight and volume immediately following euthanization. Administration of PL caused a $37 \%$ and $67 \%$ reduction in
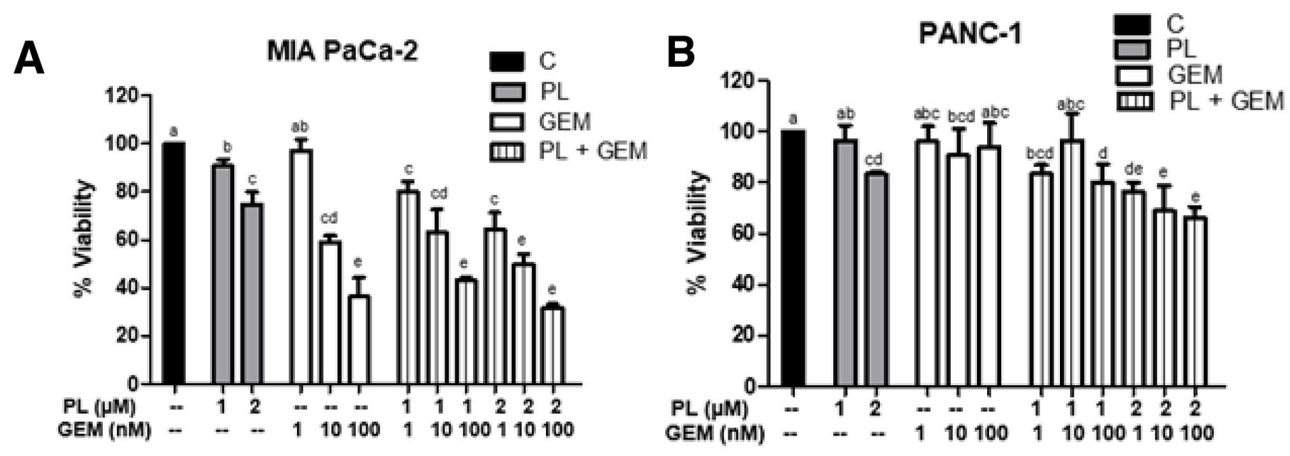

C
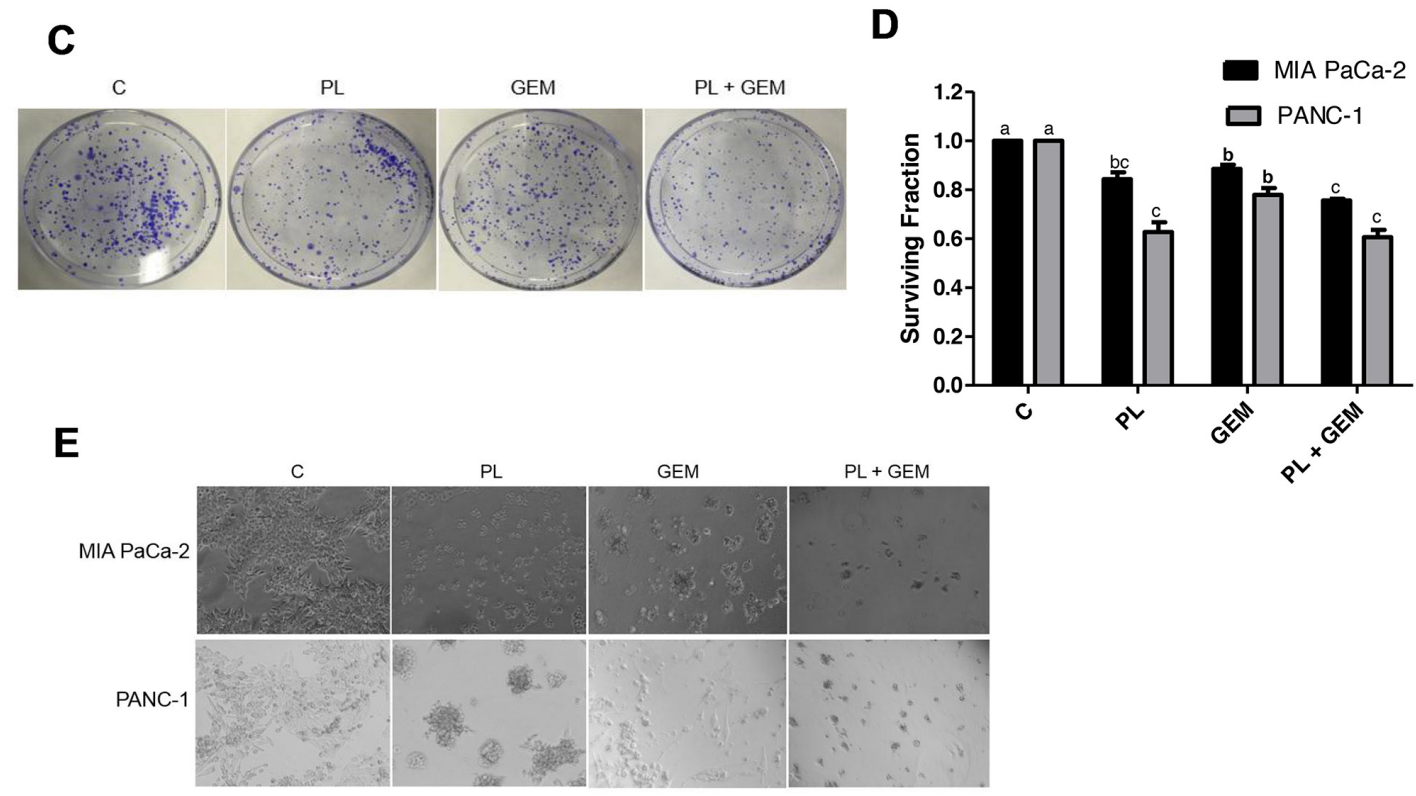

Figure 1: Effect of GEM, PL, and their combination on in vitro cell viability, clonogenic survival, and growth on Matrigel. Cell viability percentages were determined using an MTT assay for (A) MIA PaCa-2 and (B) PANC-1 cells treated with vehicle control (C), PL (1 or $2 \mu \mathrm{M})$, GEM (1-100 nM), or their combinations for $72 \mathrm{~h}$. The data shown in the bar graphs represent the average percent viability relative to the vehicle-treated control $\pm \mathrm{SE}$ for three independent experiments for both cell lines. Clonogenic survival assays were performed for MIA PaCa-2 and PANC-1 cells treated with C, PL $(1 \mu \mathrm{M})$, GEM $(1 \mathrm{nM})$, or PL $(1 \mu \mathrm{M})+\mathrm{GEM}(1 \mathrm{nM})$ for 10 days. (C) Results from a typical clonogenic survival experiment are shown for the MIA PaCa-2 cell line. (D) The number of colonies formed relative to the number of cells seeded (surviving fraction) was determined for MIA PaCa-2 and PANC-1 cells treated with PL, GEM, or their combination relative to the vehicle-treated controls. The data shown in the bar graph represent the average surviving fraction relative to vehicle-treated controls $\pm \mathrm{SE}$ for three independent experiments for each cell line. (E) MIA PaCa-2 and PANC-1 cells were grown on Matrigel and treated with C, PL $(1 \mu \mathrm{M})$, GEM $(1 \mu \mathrm{M})$, or PL $(1 \mu \mathrm{M})+\mathrm{GEM}(1 \mu \mathrm{M})$ for 4 days. The experiment was performed three times and the images show one representative experiment for each cell line. Treatments with bars that do not share a letter have differences that are statistically significant at $\mathrm{P} \leq 0.05$. 
A

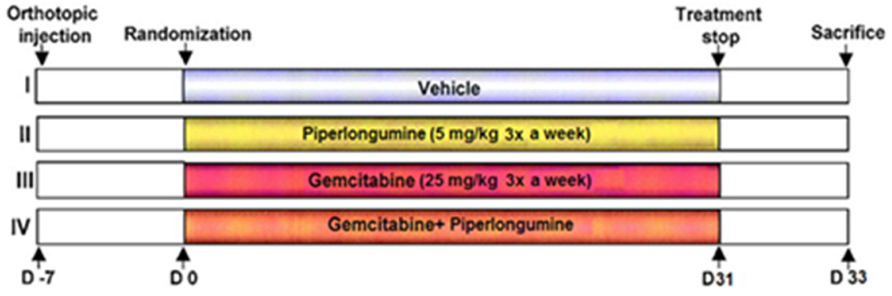

B

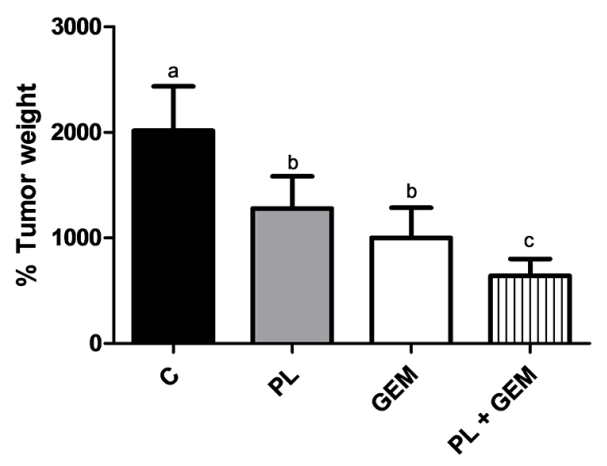

D

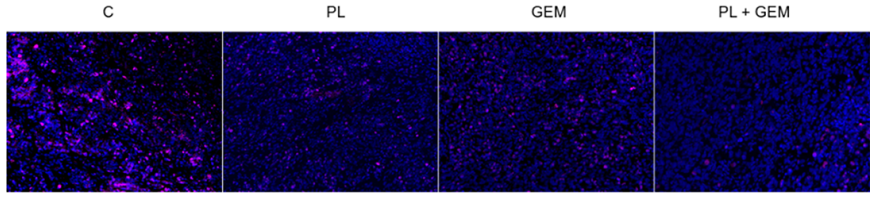

E

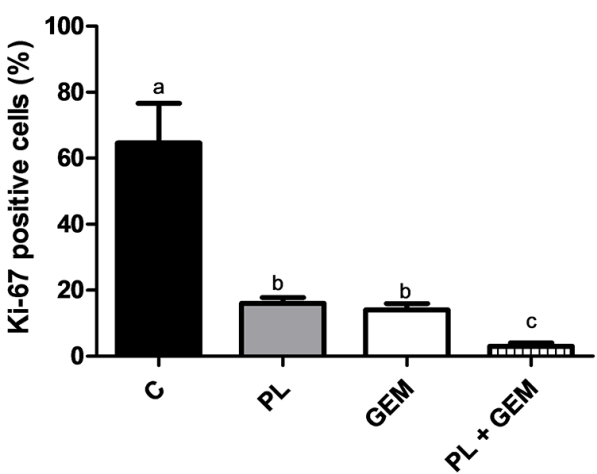

C

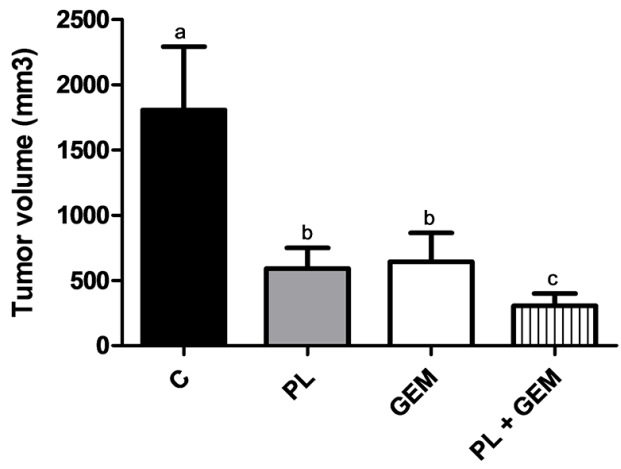

$\mathbf{F}$

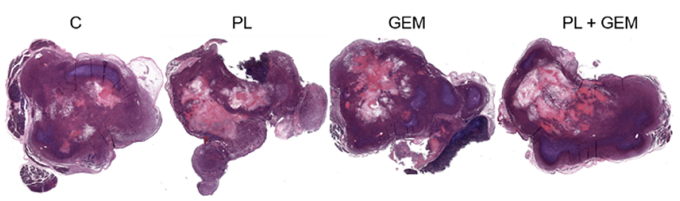

G

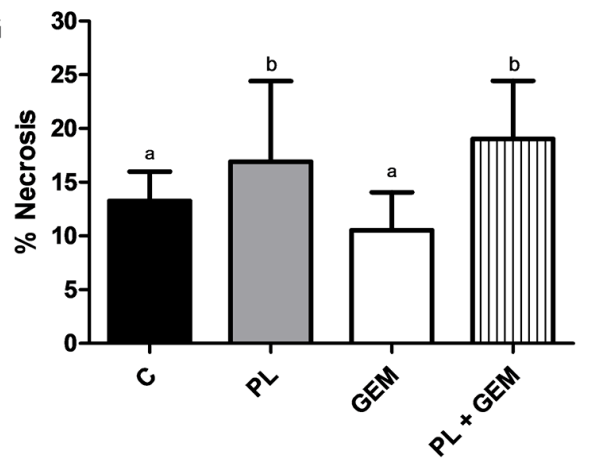

Figure 2: Effects of PL, GEM, and their combination on tumor growth, tumor cell proliferation, and tumor necrosis in mice implanted with MIA PaCa-2 cells. (A) Schematic showing the study design. MIA PaCa-2 cells were injected into the pancreata of nude mice ( $\mathrm{n}=12$ / treatment group). One week later, mice were randomized into one of four treatment groups (C, PL, GEM, or PL + GEM). Control mice received i.p. injections of the vehicle, PL mice received i.p. injections of $5 \mathrm{mg} / \mathrm{kg}$ PL, GEM mice received i.p. injections of $25 \mathrm{mg} / \mathrm{kg}$ GEM, and dual therapy mice received i.p. injections of $5 \mathrm{mg} / \mathrm{kg}$ PL and $25 \mathrm{mg} / \mathrm{kg}$ GEM three times a week for 31 days. (B) Tumor weight and $(\mathbf{C})$, tumor volume $\left[\mathrm{V}=(\text { width })^{2} \mathrm{x}\right.$ length/2] were determined at the end of the study for each treatment group. Each value in the graph is the mean \pm SE from 12 mice. (D) Tumor tissue sections from C, PL, GEM, or PL + GEM-treated mice were subjected to immunohistochemistry for Ki-67 staining. One representative image is shown for each treatment group. (E) The percentage of Ki-67 positive cells was determined for each treatment group by counting the number of Ki-67 stained cells compared to DAPI-stained cells. Each value in graph is the mean \pm SE from 4-5 mice. (F) H\&E staining of tumors was performed to identify viable pancreatic tissue compared to necrotic tissue. One representative image for each treatment group is shown. (G) The percentage of necrotic tissue was determined by subtracting the necrotic area from the total tissue section. Each value in graph is the mean \pm SE from 4-5 mice. Treatments with bars that do not share a letter have differences that are statistically significant at $\mathrm{P} \leq 0.05$. 
tumor weight and volume, respectively, compared to the control treatment (Figure 2B and 2C). GEM alone caused a $50 \%$ reduction in tumor weight and a $64 \%$ reduction in tumor volume compared to the control treatment. The combination of GEM and PL showed a significant decrease $(\mathrm{p}<0.01)$ in tumor weight $(68 \%)$ and volume $(83 \%)$ relative to the control, as well as to PL alone and GEM alone-treated mice. No macroscopic evidence of spreading to other visceral organs was evident for any experimental groups (not shown). Together, these results confirm the chemosensitizing effects of PL in an in vivo orthotopic PDAC model.

\section{Tumor cell proliferation is reduced by $\mathbf{P L}+$ GEM treatment of pancreatic tumors}

Expression of the cell proliferation marker Ki-67 was investigated by immunohistochemistry in pancreatic tumors harvested from mice treated with the vehicle control, PL, GEM, or PL + GEM. Tumors obtained from PL and GEM alone-treated mice exhibited significantly fewer Ki-67positive cells (16\% and $14 \%$, respectively) compared to control-treated mice which showed $65 \%$ Ki-67-positive cells (Figure 2D and 2E). Mice treated with PL + GEM displayed an even greater reduction in proliferating cells $(3 \%)$ relative to control-treated mice (Figure $2 \mathrm{D}$ and $2 \mathrm{E}$ ). These data provide additional evidence that PL + GEM prevents PDAC cells from proliferating in vivo.

\section{Necrosis is enhanced by PL + GEM treatment of pancreatic tumors}

Hematoxylin and eosin staining was performed to determine the effect of PL, GEM, or their combination on pancreatic tumor necrosis (Figure 2F). Tumors obtained from PL-treated mice showed $17 \%$ necrotic area compared to control-treated mice (13\%); whereas, GEM-treated mice showed 11\% necrotic area (Figure 2G). Mice treated with PL + GEM had significantly greater amounts (19\%) of necrotic tissue compared to control and GEM-treated mice. This result suggests that PL + GEM causes tumor cell death that would contribute to reduced tumor burden in mice.

\section{The combination of GEM and PL up-regulates p53 target genes and in pancreatic tumors}

To identify potential mechanisms associated with the complementary effects of PL + GEM, RNA-Seq was performed on tumors obtained from these mice. The transcriptome of control animals was compared to PL, GEM, and PL + GEM-treated mice to identify differentially expressed genes using a log2 fold-change cut off of $\leq-1$ and $\geq 1$. A total of 1,755 genes were differentially expressed in pancreatic tissues obtained from C vs. PL + GEM-treated mice compared to 25 and 715 genes for C vs. GEM or PL alone-treated mice, respectively. Out of 1,755 genes in the PL + GEM-treated tumors, 734 genes were upregulated and 1,021 genes were downregulated. Reactome software was used to identify the cellular and molecular processes involved in the antitumor effects of PL + GEM. The combination treatment modulated expression of genes involved in regulating cell death, cellular response to stress, the cell cycle, and DNA repair pathways (Figure 3A).

Ingenuity Pathway Analysis Software was used to identify the molecular pathways involved in the antitumor effects of PL + GEM. Seventy-five genes were up-regulated or down-regulated by PL + GEM treatment that were consistent with activation of p53 (activation Z-score was 2.7). These included up-regulation of cell cycle-inhibitory genes (CDKN1A, SFN, GADD45G, GADD45GIP1, G0S2, MAPK12, PTTG1, and BORA) and down-regulation of cell cycle-promoting genes (CCNE2, CCNG2, CCNK, TTK, and WEE1). Further, apoptosis-promoting genes (PIDD1, BIK, MAPK11, PANO1, NFKBID, and NFKBIE) were up-regulated while apoptosis-inhibiting genes (XAF1, CAAP1, and REL) were down-regulated in PL + GEM-treated tumors (Figure 3B).

PL and GEM both induce oxidative stress; therefore, it was not surprising to observe over-expression of several oxidative stress response genes in the tumors of PL + GEM-treated mice. Detoxification enzymes, including GPX1, GPX4 CYBA, PRDX5, CCS, and ATOX1 were up-regulated in the combination treatment compared to controls (Figure 3B). Further, eleven different subunits of NADH:ubiquinone oxidoreductase (complex I), a major source of ROS in mitochondria, were significantly elevated in PL + GEM-treated tumors (Supplementary Data). Together, the RNA-Seq results lend support to the hypothesis that PL + GEM elevates ROS levels in tumor cells which leads to DNA damage and transcription of cell cycle arrest and apoptosis-associated genes (Figure 3B).

\section{The combination of PL and GEM increases ROS levels in PDAC cells compared to GEM alone}

PL and GEM are both known to elevate ROS levels in cancer cells $[9,26]$, which are already under metabolic stress. Our RNA-Seq results directed us to evaluate if PL and GEM in combination could further enhance ROS levels. We postulated that the growth-inhibitory effects of combining these two agents could be a result of elevating ROS levels to a potentially lethal or near-lethal degree. To determine if PL + GEM could enhance ROS levels beyond either agent alone, we conducted an ROS assay in PDAC cells. PANC-1 cells were treated with PL (10 $\mu \mathrm{M})$, GEM (10 $\mu \mathrm{M})$, or PL + GEM (10 $\mu \mathrm{M}$ each) for $1 \mathrm{hr}$. The cells were stained with the fluorescent dye DCFDA to detect ROS, and fluorescence was determined using flow cytometry. PL + GEM significantly increased ROS levels compared to control and GEM, but not PL alone (Figure $4 \mathrm{~A})$. These results suggested the possibility that the 
combination of PL + GEM decreases PDAC cell growth by elevating ROS levels.

\section{$P L+G E M$ induces arrest at $G_{0} / G_{1}$ phase of the cell cycle}

Increased ROS levels can activate transcription factors and trigger changes in expression of cell cycle regulatory proteins that inhibit progression of cells through the cell cycle. Our RNA sequencing data revealed PL + GEM decreased expression of CCNE1 (cyclin E1) and increased expression of CDKN1A (p21), critical genes that help regulate the cell cycle. Therefore, we performed cell cycle profiling experiments to identify the effects of PL + GEM on PDAC cells. MIA PaCa- 2 and PANC-1 cells were treated with PL $(5 \mu \mathrm{M})$, GEM $(100 \mathrm{nM})$, or PL $(5 \mu \mathrm{M})+$ GEM $(100 \mathrm{nM})$ for $24 \mathrm{~h}$, after which cell cycle profiling was determined using PI staining and flow cytometry. Figure 4B and 4C show PL + GEM caused more cell cycle arrest at the $\mathrm{G}_{0} / \mathrm{G}_{1}$ phase in both PDAC cell lines compared to the control and individual treatments. A concomitant decrease in the $\mathrm{G}_{2} / \mathrm{M}$ population

A

Cell cycle Cellular response to stress

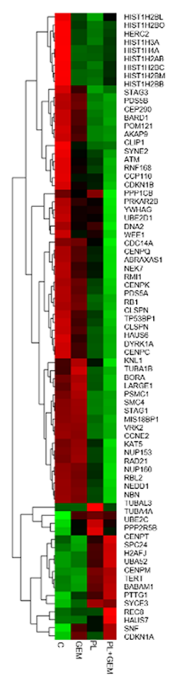

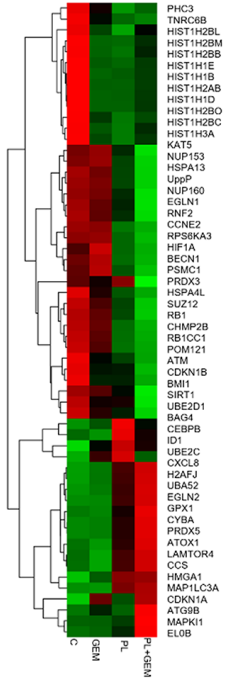

DNA repair

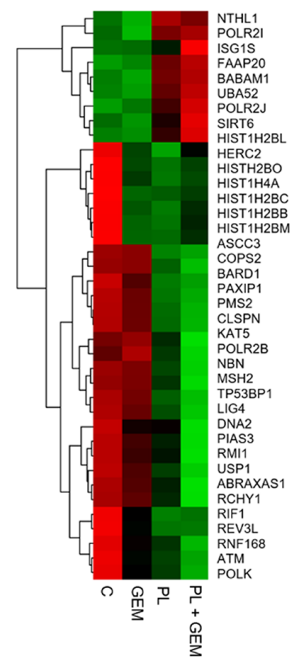

Programmed cell death

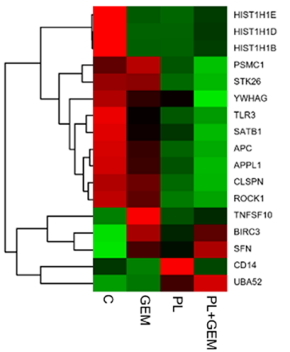

Detoxification of ROS

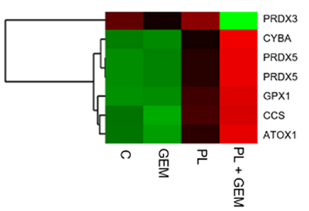

B

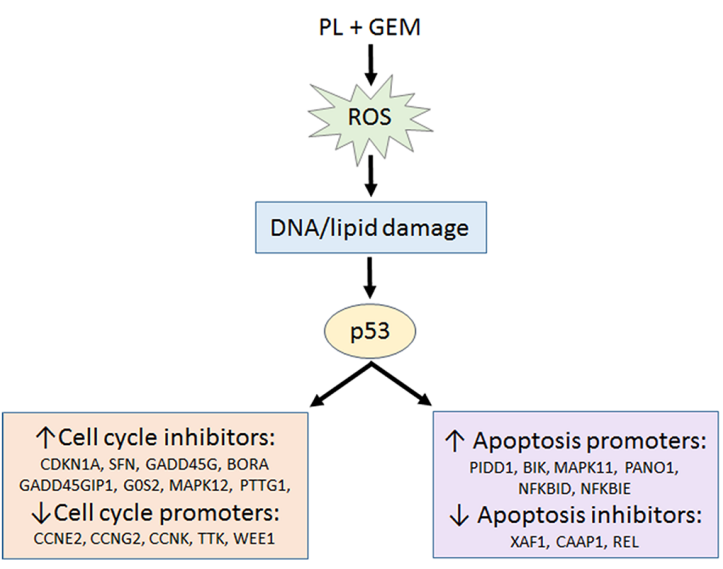

Figure 3: Effect of PL, GEM, and their combination on gene expression in orthotopic pancreas tumors and a proposed mechanism for their complementary anti-tumor effects. RNA-Seq was performed on MIA PaCa-2 xenograft tumors obtained from C, GEM, PL, and PL + GEM-treated mice. (A) Heat maps for differentially expressed genes from five distinct pathways (cell cycle, cellular response to stress, DNA repair, programmed cell death, and detoxification of ROS) are shown for the four treatment groups (C, GEM, PL, and GEM + PL; n=3 each). The color gradient represents low (green) to high (red) levels of expression. (B) Proposed mechanism for the complementary anti-tumor effects of PL + GEM based on RNA-Seq data. The gene expression data indicate that PL + GEM alters the expression of a host of p53-responsive genes. PL + GEM increased a variety of cell cycle inhibitors and decreased cell cycle promoters. Further, PL + GEM increased apoptosis promoters and decreased apoptosis inhibitors. 

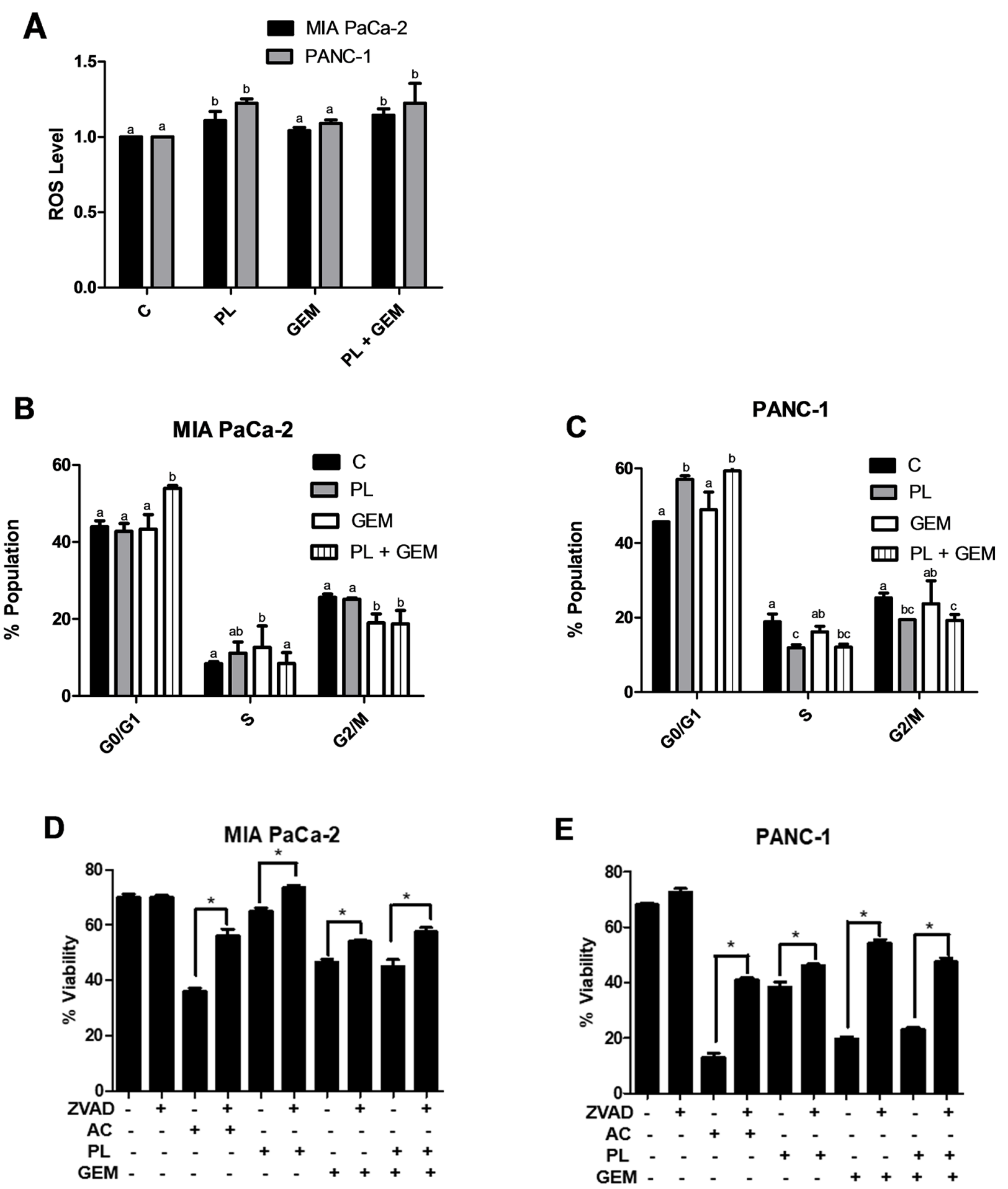

Figure 4: Effect of PL, GEM, and their combination on ROS levels, cell cycle profile, and viability. (A) ROS levels were determined using DCFDA for MIA PaCa-2 and PANC-1 cells treated with vehicle control (C), PL (10 $\mu \mathrm{M})$, GEM (10 $\mu \mathrm{M})$, or PL $(10 \mu \mathrm{M})$ + GEM $(10 \mu \mathrm{M})$ for $1 \mathrm{~h}$. Cell cycle profiling was determined using propidium iodide for (B), MIA PaCa-2 and (C), PANC-1 cells treated with vehicle control (C), PL $(5 \mu \mathrm{M})$, GEM $(100 \mathrm{nM})$, or PL $(5 \mu \mathrm{M})+$ GEM $(100 \mathrm{nM})$ for $24 \mathrm{~h}$. The data shown in the bar graphs represent the average percent population in the given cell cycle phases \pm SE for each treatment group. The experiment was conducted at least three times for each cell line. Treatments with bars that do not share a letter have differences that are statistically significant at $\mathrm{P} \leq 0.05$. A cell viability assay was performed for (D), MIA PaCa-2 and (E), PANC-1 cells treated with vehicle control (C), ZVAD (30 $\mu$ M), actinomycin (AC; $1 \mu \mathrm{g} / \mathrm{mL})$, PL $(4 \mu \mathrm{M})$, GEM $(0.5 \mu \mathrm{M})$, or their combinations for $48 \mathrm{~h} .{ }^{*}$ indicates a significant change in viability for a treatment group with respect to that treatment group combined with the caspase inhibitor ZVAD. 
of cells was observed for PL + GEM-treated PDAC cells relative to control and individual treatment. These results suggest that arrest of the cell cycle in the $\mathrm{G}_{0} / \mathrm{G}_{1}$ phase is a likely mechanism by which PL + GEM prevents PDAC cell proliferation.

\section{GEM, in combination with PL, reduces cell viability}

Similarly, elevated ROS levels can trigger cell death by pushing cells over a toxicity threshold. Our RNA-Seq data (elevated caspase-9 and reduced NF-KB expression) showed that GEM in combination with PL affected the expression of apoptosis-related genes in a manner suggesting increased apoptosis. Therefore, we performed a viability assay for MIA PaCa-2 and PANC-1 cells treated with actinomycin D (positive control), PL (4 $\mu \mathrm{M})$, GEM $(0.5 \mu \mathrm{M})$, and PL $(4 \mu \mathrm{M})+\operatorname{GEM}(0.5 \mu \mathrm{M})$ with or without Z-VAD (caspase inhibitor) for $48 \mathrm{~h}$. We found that PL + GEM caused a $44 \%$ and $25 \%$ decrease in PDAC cell viability compared to control-treated PANC-1 and MIA PaCa-2 cells, respectively (Figure 4D and 4E). Additionally, the caspase inhibitor Z-VAD blocked about $50 \%$ and $30 \%$ of PANC- 1 and MIA PaCa- 2 cell death, respectively. This result suggests that GEM in combination with PL caused apoptosis in a caspase-dependent manner for both PDAC cell lines. Interestingly, PANC-1 cells undergo more caspase-dependent cell death in response to PL + GEM than MIA PaCa-2 cells, which suggests that ROS-induced cell death mechanisms may differ based on PDAC subtype [27, 28].

\section{DISCUSSION}

Effective treatment options are not currently available for advanced stage PDAC. GEM along with other adjuvants are used in combination to treat PDAC. However, these approaches have had limited success and only extend life span by months with added toxicity [5-7]. In this study, we determined that a small molecule obtained from a natural product enhances the effects of GEM in preclinical models of PDAC. We found that GEM in combination with PL significantly impaired stressinduced growth of PDAC cells in vitro and reduced tumor growth and weight compared to vehicle-control and to single-agent treatment in an orthotopic pancreatic mouse model. We propose that PL complements GEM's effect by increasing ROS levels, inducing DNA damage, and leading to cell cycle arrest and apoptosis.

Several combination therapies have been evaluated in clinical trials and are currently used for PDAC treatment, such as GEM with erlotinib, Cetuximab, or nabpaclitaxel; however, the outcomes have been disappointing $[19,21,22,23,24]$. In addition to dismal outcomes of chemotherapeutics, chemo-resistance and unwanted side effects in healthy tissues remain a problem. Recently,
FOLFIRINOX, a cocktail of fluorouracil, leucovorin, irinotecan and oxaliplatin, has been widely used as a first line treatment for PDAC. While the overall survival for patients treated with FOLFIRINOX was 11.1 months compared to 6.8 months for the GEM-treated group, FOLFIRINOX causes significant side effects and is poorly tolerated [29].

Preclinical data suggest that ROS inducers are a promising therapeutic for treating various cancers, including PDAC $[12,30,31]$. We have previously shown that PL inhibits PANC-1 tumor progression in a subcutaneous model by inducing oxidative stress, DNA damage, and cell death [10]. Additionally, we have identified 683 gene transcripts significantly modulated by PL treatment in MIA PaCa- 2 cells which included upregulation of ER-stress and oxidative stress-associated genes [11]. The results from the experiments presented here build upon our previous observations, and provide a rationale for the use of a ROS-inducer such as PL in KRAS-mutant tumors like PDAC.

Previous studies have shown that combining GEM with an ROS inducer enhances PDAC cell death in vitro and in vivo $[32,33]$. Here we show that the ROS inducer, $\mathrm{PL}$, enhanced the therapeutic efficacy of GEM for two different PDAC cell lines (PANC-1 and MIA PaCa-2) that respond quite differently to GEM [18]. The three in vitro assays we used (MTT, clonogenic survival, and Matrigel growth) provided interesting results for the two PDAC cell lines which have similar genetic backgrounds (KRAS, TP53, CDKN2A mutant and SMAD4 wild type) [20], but unique surface markers and metabolic profiles [21, 22]. MIA PaCa-2 cells are more glycolysic and mesencymal-like whereas PANC-1 cells are more lipogenic and epithelial-like. MIA PaCa-2 cells were more sensitive to GEM in the MTT assay than PANC1 , but not the clonogenic survival or Matrigel assays. When PANC-1 cells were seeded at low density or under the growth-stressed conditions of Matrigel, they showed similar sensitivities as MIA PaCa-2 to PL, GEM, and PL + GEM. The reasons for this might be due to differences in cell adhesion protein expression that would more greatly impact the growth of PANC-1 cells in low-density contexts than MIA PaCa-2, and the cells' abilities to grow on different substrates [22] such as Matrigel.

In support of our in vitro results, we further showed that a PL (5 mg/kg, 3x weekly, i.p., 31 days) plus GEM (25 mg/kg, 3x weekly, i.p., 31 days) significantly reduced tumor size compared to control-treated or single agenttreated mice. Recently, PL + GEM was shown to induce apoptosis and inhibit BxPC-3 (KRAS wildtype, BRAF mutant) pancreatic tumor growth in a subcutaneous model [34]. This group found that PL (10 mg/kg, once daily, i.p, 24 days) enhanced the therapeutic efficacy of GEM (100 $\mathrm{mg} / \mathrm{kg}$, twice weekly, i.p, 24 days) for PDAC, lending additional support for the use of PL in combination with GEM to treat PDAC. 
The anticancer mechanisms of PL have been evaluated in several different cancers, but are not well studied in PDAC. Previous reports have shown PL causes cell cycle arrest in the $\mathrm{G}_{2} / \mathrm{M}$-phase via induction of GADD45A in gastric cancer cells and $\mathrm{G}_{0} / \mathrm{G}_{1}$-phase arrest via elevation of CDKN1A expression in oral squamous cancer cells $[35,36]$. Our RNA sequencing data showed $\mathrm{PL}+\mathrm{GEM}$ enhanced expression of p53-responsive genes including the cell cycle-associated genes CDKN1A, SFN, and GADD45G, and reduced expression of CCNE2, $\mathrm{CCNG} 2$, and $\mathrm{CCNK}$ in pancreatic tumors. Furthermore, our cell cycle profiling confirmed that cells treated with $\mathrm{PL}+\mathrm{GEM}$ caused cell cycle arrest at the $\mathrm{G}_{0} / \mathrm{G}_{1}$ phase. In addition to causing cell cycle arrest, PL has been shown to induce cancer cell death through a variety of mechanisms including decreased DNA binding activity of the prosurvival transcription factor NF- $\mathrm{B}$ in non-small cell lung cancer [37], activated MEK/ERK signaling in colon cancer cells [38, 39], elevated HO-1 via Nrf-2 signaling in breast cancer [40], and modulated JNK and PARP pathways in head and neck cancer [41]. Similarly, our RNA sequencing data showed PL decreased the expression of the NF-KB subunit transcript REL and increased the expression of the NF-KB inhibitors NFKBID and NFKBIE which could activate caspase-9 and cause apoptosis. Finally, we showed that PL + GEM caused cell death in PANC-1 cells and, to a lesser extent, MIA PaCa-2 cells through a caspase-dependent mechanism. Collectively, our results suggest that PL + GEM enhances ROS levels, which ultimately leads to cell cycle arrest and apoptosis.

Further evaluation of PL alone and in combination with GEM or other chemotherapies is needed to better understand the potential use of PL in a clinical setting. A limitation of the current study was the use of only one concentration of PL and GEM along with a single dosing schedule in the animal experiments. A more comprehensive study evaluating different doses and treatment schedules is needed. Further, it is not clear what effects PL + GEM might have on normal pancreatic cells. Given the selective toxicity of PL for cancer cells, it is possible that PL + GEM will not introduce additional toxicity to normal tissues, and this should be investigated. Further, it will be important to evaluate PL + GEM in the context of other animal models of PDAC including transgenic (immunocompetent) or patient derived xenografts which retain tumor architecture. Altogether, these results support PL's use as a promising complementary therapy to the anti-tumor effects of GEM in PDAC.

\section{MATERIALS AND METHODS}

\section{Reagents}

Piperlongumine (PL) was purchased from Indofine Chemical Company. Gemcitabine hydrochloride (GEM) was purchased from Sigma-Aldrich. PL and GEM were dissolved in $100 \%$ DMSO at stock concentrations of 100 $\mathrm{mM}$ and diluted in medium to working concentrations. Matrigel matrix was obtained from Corning. DCFDA was purchased from Life Technologies. Ki-67 antibody was purchased from Vector Labs. CF633-conjugated goat anti-mouse IgG secondary antibody was obtained from Biotium.

\section{Cell culture}

PDAC cell lines (MIA PaCa-2 and PANC-1) were purchased from the American Type Culture Collection and grown at $37^{\circ} \mathrm{C}$ with $5 \% \mathrm{CO}_{2}$. MIA PaCa-2 cells were cultured in DMEM high-glucose medium (Thermo Fisher Scientific) supplemented with $10 \%$ fetal bovine serum (Atlanta Biologicals) and 2.5\% horse serum (Corning). PANC-1 cells were cultured in DMEM high-glucose medium supplemented with $10 \%$ fetal bovine serum. The cell lines were sub-cultured by enzymatic digestion with $0.25 \%$ trypsin/ $1 \mathrm{mM}$ EDTA solution (Thermo Fisher Scientific) when they reached approximately $70 \%$ confluency.

\section{Cell viability assay}

MIA PaCa-2 and PANC-1 cells (1,500 cells/well) were seeded in 96-well plates, and $48 \mathrm{~h}$ or $24 \mathrm{~h}$ later, respectively, were treated with different concentrations of PL (1 or $2 \mu \mathrm{M})$, GEM $(1,10$, or $100 \mathrm{nM})$ or their combinations for $72 \mathrm{~h}$. Drug concentrations were optimized for each cell-based assay. A cell viability assay was performed by adding $10 \mu \mathrm{l}$ of 3-(4,5-dimethylthiazol2-yl)-2,5-diphenyltetrazolium bromide (MTT) reagent to each well and incubating the plates for $2 \mathrm{~h}$ at $37^{\circ} \mathrm{C}$. The MTT reagent was removed, DMSO (100 $\mu \mathrm{L} /$ well) was added to solubilize the crystals, and absorbance was measured at $570 \mathrm{~nm}$. The data represent the average \pm standard deviation for three independent experiments.

\section{Evaluation of synergistic effects by Jin's formula}

The synergistic effects of combined PL and GEM were analyzed by Jin's formula. The formula is $\mathrm{Q}=$ $(\mathrm{Ea}+\mathrm{b}) /((\mathrm{Ea}+\mathrm{Eb})-(\mathrm{Ea} \times \mathrm{Eb}))$, where $\mathrm{Ea}+\mathrm{b}, \mathrm{Ea}$, and $\mathrm{Eb}$ are the average inhibitory effects of PL + GEM, PL alone, and GEM alone, respectively. In this method, $\mathrm{Q}<0.85$ indicates antagonism, $0.85<\mathrm{Q}<1.15$ indicates additive effects, and $\mathrm{Q}>1.15$ indicates synergism. The Ea+b, Ea, and $\mathrm{Eb}$ values were obtained from MTT assays.

\section{Clonogenic survival assay}

MIA PaCa-2 and PANC-1 cells (500 cells/dish) were seeded into $60 \mathrm{~mm}$ dishes. The next day, the cells were treated with PL (1 $\mu \mathrm{M})$, GEM (1 nM), or PL (1 $\mu \mathrm{M})+\operatorname{GEM}(1 \mathrm{nM})$, for 10 days. After 10 days, the 
cells were fixed (methanol:acetic acid, 3:1) for $15 \mathrm{~min}$. The fixing reagent was removed and the colonies were stained with $0.5 \%$ crystal violet (in methanol) for $15 \mathrm{~min}$. Finally, the cells were washed with water, and colonies were counted manually to determine the surviving fraction. Representative images of the cell culture dishes show surviving colonies for each treatment group. Data shown represent the average \pm standard deviation for the surviving cell fraction for three independent experiments for each cell line.

\section{Matrigel cell growth assay}

Matrigel was thawed on ice overnight at $4^{\circ} \mathrm{C}$. Matrigel $(50 \mu \mathrm{L} /$ well $)$ was placed on the bottom of a 48-well plate and incubated at $37^{\circ} \mathrm{C}$ for $30 \mathrm{~min}$. After incubation, MIA PaCa- 2 or PANC- 1 cells $(4,000$ cells/ well) were seeded on top of the Matrigel layer. After 48 $\mathrm{h}$, cells were treated with PL $(1 \mu \mathrm{M})$, GEM $(1 \mu \mathrm{M})$, or $(1 \mu \mathrm{M})+\mathrm{GEM}(1 \mu \mathrm{M})$. Images were taken 4 days after treatment. The experiment was repeated at least three times, and results shown represent one typical experiment for each cell line.

\section{Orthotopic mouse model of PDAC}

Six- to 8-week-old female athymic nude mice $(\mathrm{Nu} /$ $\mathrm{Nu}$ ) were purchased from Charles River Laboratories (Wilmington, MA). The mice were maintained in sterile conditions using the Innovive IVC System (Innovive), following a protocol approved by North Dakota State University's Institutional Animal Care and Use Committee. The mice were acclimated for 1 week before experimental manipulation. MIA $\mathrm{PaCa}-2$ cells were harvested and resuspended in PBS. Mice were anesthetized with a ketamine-xylazine solution, a small left abdominal flank incision was made, and MIA PaCa-2 cells $\left(\sim 8 \times 10^{5}\right.$ in $\left.30 \mu \mathrm{L}\right)$ were injected into the pancreas using a 27-gauge needle. The abdomen was closed using a 2-layer suture technique involving chromic catgut and ethilon sutures. Two weeks after cancer cell implantation, the mice were randomized into 4 groups and treated i.p. 3x/week as follows: (i) untreated control (DMSO 5\% v/v), (ii) PL ( $5 \mathrm{mg} / \mathrm{kg}$ body weight), (iii) GEM (25 mg/kg), and (iv) PL + GEM (5 mg/kg and $25 \mathrm{mg} / \mathrm{kg}$, respectively). PL was dissolved in DMSO at a stock concentration of 9.9 $\mathrm{mg} / \mathrm{ml}$ and further diluted in PBS before administering to the mice. The final concentration of DMSO in the PL working solution was 5\% v/v. GEM was dissolved in sterile saline at a stock concentration of $50 \mathrm{~g} / \mathrm{L}$. Each treatment group contained 12 animals. After 4 weeks of treatment, the animals were euthanized by an overdose of ketamine-xylazine solution followed by cervical dislocation. The primary tumors in the pancreata were excised and measured for tumor weight and volume [V= (width) $)^{2} \mathrm{x}$ length/2]. The tumor weight and volume were compared between groups using an unpaired Student's $t$-test. Tumors from half of the mice for each treatment were paraformaldehyde-fixed and paraffin-embedded for immunohistochemistry. The other half of the mouse tumors were snap-frozen in liquid nitrogen and stored at $-80^{\circ} \mathrm{C}$.

\section{Immunohistochemistry and tissue histology}

Tumor tissues from control, PL, GEM, and PL + GEM-treated mice were collected and fixed for $24 \mathrm{~h}$ in formaldehyde. Paraffin-embedded $5 \mu \mathrm{m}$ thick sections of tumor tissues were prepared. Sections were deparaffinized with Histo-Clear and ethanol, followed by antigen retrieval in $10 \mathrm{mM}$ sodium citrate buffer $(0.05 \%$ Tween $20, \mathrm{pH} 6.0)$ using an autoclave method. The sections were blocked for $20 \mathrm{~min}$ in blocking buffer $(10 \%$ normal goat serum in TBST) and incubated with Ki-67 (1:100) or overnight at $4^{\circ} \mathrm{C}$. The next day, sections were incubated with CF633conjugated goat anti-mouse secondary antibody (1:250) for $1 \mathrm{~h}$ at room temperature. For H\&E staining, tissue slides were rehydrated, stained with hematoxylin for $5 \mathrm{~min}$, washed with distilled water, soaked in $95 \%$ ethanol for 30 sec, stained with eosin for $1 \mathrm{~min}$, dehydrated with $100 \%$ ethanol for $1 \mathrm{~min}$, and washed in xylene. After mounting a coverslip using Hardset Mounting Medium with DAPI (Vector Labs, Burlingame, CA), slides were visualized using a Zeiss inverted Axio Observer Z1 microscope. The percentage of Ki-67-positive cells was measured based on the number of pink-stained cells relative to the number of blue DAPI-stained nuclei. The percentage of necrotic cells was determined based on the area of light pink subtracted from total area on $\mathrm{H} \&$ E-stained sections.

\section{RNA extraction}

Total RNA was extracted from pancreatic tumors from each group using TRI Reagent (Life Technologies). Briefly, $5 \mathrm{mg}$ of tissue was homogenized in $1 \mathrm{~mL}$ of TRI Reagent and incubated at room temperature for $15 \mathrm{~min}$. Next, $50 \mu \mathrm{L}$ of BCP was added. The tube was shaken vigorously for $30 \mathrm{~s}$, incubated again at room temperature for $3 \mathrm{~min}$, and then centrifuged at $12,000 \mathrm{xg}$ for $15 \mathrm{~min}$ at $4{ }^{\circ} \mathrm{C}$. The supernatant was transferred to a fresh tube, and total RNA was precipitated by adding 1.5 volumes of $100 \%$ ethanol. The precipitated RNA sample was transferred to an RNeasy Mini spin column (Qiagen), and RNA purification was performed using the manufacturer's protocol.

\section{RNA-Sequencing}

Three micrograms of total RNA from three mice in each group: control, PL, GEM, and PL + GEM were sent for sequencing at the University of Minnesota Genomics Center. Six barcoded libraries were created and sequenced on an Illumina HiSeq 2500. Single-end reads of 50 base pairs (bp) were obtained and mapped to the Mus musculus 
genome (Build: Mus_musculus.GRCm38) downloaded from Ensembl. The raw fastq data were subjected to quality trimming using Sickle, for a minimum length of 50. HISAT2 [13] was used to map the reads on the genome. SAMtools [14] and BAMtools [15] were used to convert and sort the BAM files. HTSeq [16] was used to count the reads.

\section{Cell cycle arrest assay}

Briefly, PDAC cell lines (MIA PaCa-2 and PANC1) were seeded in 6-well plates and incubated overnight. Cells were then synchronized overnight using serum free medium. Next, cells were treated with PL $(5 \mu \mathrm{M})$, GEM (100 nM), or $5 \mu \mathrm{M}$ PL $+100 \mathrm{nM}$ GEM for $24 \mathrm{~h}$. Cells were then harvested by trypsinization, washed, and resuspended in $70 \%$ ethanol overnight at $4{ }^{\circ} \mathrm{C}$. Finally, cells were re-suspended in PBS containing $50 \mu \mathrm{g} / \mathrm{mL}$ propidium iodide (PI) and $1 \mu \mathrm{g} / \mathrm{mL}$ of RNase A. Flow cytometry was performed to determine the percentage of cells in each phase of the cell cycle.

\section{Viability assay}

A viability assay was performed using PI staining followed by flow cytometry. Briefly, PDAC cell lines (MIA PaCa-2 and PANC-1) were seeded in 6-well plates and incubated overnight. Cells were then treated with and without Z-VAD $(25 \mu \mathrm{M})$ for $30 \mathrm{~min}$ at $37^{\circ} \mathrm{C}$. Next, cells were treated with actinomycin D $(1 \mu \mathrm{g} / \mathrm{ml})$, PL $(4 \mu \mathrm{M})$, GEM $(0.5 \mu \mathrm{M})$, or PL + GEM (4 $\mu \mathrm{M}+0.5$ $\mu \mathrm{M}$, respectively) for $48 \mathrm{~h}$. Cells were then harvested by trypsinization, washed, and re-suspended in PBS containing $1 \mu \mathrm{g} / \mathrm{mL}$ of PI. Flow cytometry was performed to determine the percentage of PI-positive cells as an indication of overall viability.

\section{Measurement of ROS levels by the 2,7-dichlorodihydrofluorescein diacetate (DCFDA) assay}

MIA PaCa- 2 and PANC- 1 cells $\left(5.0 \times 10^{5}\right.$ cells $\left./ \mathrm{ml}\right)$ were suspended in culture medium and treated with PL $(10 \mu \mathrm{M})$, GEM $(10 \mu \mathrm{M})$, or their combinations $(10 \mu \mathrm{M}$ $\mathrm{PL}+10 \mu \mathrm{M}$ GEM) for $1 \mathrm{~h}$. After treatment, cells were harvested by centrifugation and re-suspended in $20 \mu \mathrm{M}$ DCFDA in PBS. The cells were incubated at $37^{\circ} \mathrm{C}$ for 30 min before flow cytometric analysis using an Accuri C6 Flow Cytometer. Three technical replicates were included for each experiment, and the experiments were performed in biological triplicates for each cell line.

\section{Statistical analyses}

Statistical analyses were performed in SAS version 9.4 using the PROC MIXED procedure. Analysis of variance (ANOVA) was conducted for each analysis. All analyses included "treatment" as the main fixed effect in the ANOVA model. For experiments conducted over time, "time" was included in the model as a fixed effect. For analysis of data that involved experiments repeated independently, "experiment" was included in the model as a blocking effect. Finally, for the MTT assay fold change analysis, "plate" was treated as a random effect. Post-hoc $t$-tests were performed to compare each pair of treatments. Differences were considered statistically significant for $\mathrm{P}$ $<0.05$.

\section{Abbreviations}

3-(4, 5-dimethylthiazol-2-yl)-2, 5-diphenyltetra zolium bromide (MTT), gemcitabine (GEM), pancreatic ductal adenocarcinoma (PDAC), piperlongumine (PL), propidium iodide (PI), reactive oxygen species (ROS), RNA sequencing (RNA-Seq).

\section{ACKNOWLEDGMENTS}

We thank Dr. Adrienne Cox for her excellent editorial comments and suggestions.

\section{CONFLICTS OF INTEREST}

The authors declair no conflicts of interest.

\section{AUTHOR FINANCIAL SUPPORT}

Funding for this project was made possible by NIH Grant Numbers 1P20GM109024, P30GM103332, and 1U54GM115458-01 (to KMR) from the National Institute of General Medicine (NIGMS) and NIH Grant Number 1R15CA206067 (to JCW) from the National Cancer Institute (NCI). Its contents are solely the responsibility of the authors and do not necessarily represent the official views of the NIH.

\section{REFERENCES}

1. Siegel RL, Miller KD, Jemal A. Cancer Statistics, 2017. CA Cancer J Clin. 2017; 67: 7-30. https://doi.org/10.3322/ caac. 21387.

2. Stathis A, Moor MJ. Advanced pancreatic carcinoma: current treatment and future challenges. Nat Rev Clin Oncol. 2010; 7: 163-72. https://doi.org/10.1038/ nrclinonc.2009.236.

3. Oettle H, Post S, Neuhaus P, Gellert K, Langrehr J, Ridwelski K, Schramm H, Fahlke J, Zuelke C, Burkart C, Gutberlet K, Kettner E, Schmalenberg H, Weigang-Koehler $\mathrm{K}$, et al. Adjuvant chemotherapy with gemcitabine vs observation in patients undergoing curative-intent resection of pancreatic cancer: a randomized controlled trial. JAMA. 2007; 297: 267-77. https://doi.org/10.1001/jama.297.3.267. 
4. Ahn DH, Williams TM, Goldstein DA, El-Rayes B, BekaiiSaab T. Adjuvant therapy for pancreas cancer in an era of value based cancer care. Cancer Treatment Reviews. 2016; 42: 10-17. https://doi.org/10.1016/j.ctrv.2015.11.004.

5. Heinemann V, Quietzsch D, Gieseler F, Gonnermann M, Schönekäs H, Rost A, Neuhaus H, Haag C, Clemens M, Heinrich B, Vehling-Kaiser U, Fuchs M, Fleckenstein D, et al. Randomized phase III trial of gemcitabine plus cisplatin compared with gemcitabine alone in advanced pancreatic cancer. J Clin Oncol. 2006; 24: 3946-52. https://doi. org/10.1200/JCO.2005.05.1490.

6. Von Hoff DD, Ervin T, Arena FP, Chiorean EG, Infante J, Moore M, Seay T, Tjulandin SA, Ma WW, Saleh MN, Harris M, Reni M, Dowden S, et al. Increased survival in pancreatic cancer with nab-paclitaxel plus gemcitabine. N Engl J Med, 2013; 369: 1691-703. https://doi.org/10.1056/ NEJMoa1304369.

7. Berlin JD, Catalano P, Thomas JP, Kugler JW, Haller DG, Benson AB $3^{\text {rd }}$. Phase III study of gemcitabine in combination with fluorouracil versus gemcitabine alone in patients with advanced pancreatic carcinoma: Eastern Cooperative Oncology Group Trial E2297. J Clin Oncol. 2002; 20: 3270-5. https://doi.org/10.1200/JCO.2002.11.149.

8. Bezerra DP, Castro FO, Alves AP, Pessoa C, Moraes MO, Silveira ER, Lima MA, Elmiro FJ, Costa-Lotufo LV. In vivo growth-inhibition of Sarcoma 180 by piplartine and piperine, two alkaloid amides from Piper. Braz J Med Biol Res. 2006; 39: 801-7. doi: S0100-879X2006000600014.

9. Raj L, Ide T, Gurkar AU, Foley M, Schenone M, Li X, Tolliday NJ, Golub TR, Carr SA, Shamji AF, Stern AM, Mandinova A, Schreiber SL, Lee SW. Selective killing of cancer cells by a small molecule targeting the stress response to ROS. Nature. 2011, 475: 231-4.

10. Dhillon H, Chikara S, Reindl KM. Piperlongumine induces pancreatic cancer cell death by enhancing reactive oxygen species and DNA damage. Toxicol Rep. 2014; 1: 309-318. https://doi.org/10.1016/j.toxrep.2014.05.011.

11. Dhillon H, Mamidi S, McClean P, Reindl KM. Transcriptome Analysis of Piperlongumine-Treated Human Pancreatic Cancer Cells Reveals Involvement of Oxidative Stress and Endoplasmic Reticulum Stress Pathways. J Med Food. 2016; 19: 578-85. https://doi.org/10.1089/ jmf.2015.0152.

12. Trachootham D, Zhou Y, Zhang H, Demizu Y, Chen Z, Pelicano H, Chiao PJ, Achanta G, Arlinghaus RB, Liu J, Huang P. Selective killing of oncogenically transformed cells through a ROS-mediated mechanism by betaphenylethyl isothiocyanate. Cancer Cell, 2006; 10: 241-252. https://doi.org/10.1016/j.ccr.2006.08.009.

13. Kim D, Langmead B, Salzberg SL. HISAT: a fast spliced aligner with low memory requirements. Nat Methods. 2015; 12: 357-60. https://doi.org/10.1038/nmeth.3317.

14. Li H. A statistical framework for SNP calling, mutation discovery, association mapping and population genetical parameter estimation from sequencing data. Bioinformatics.
2011; 27: 2987-93. https://doi.org/10.1093/bioinformatics/ btr509.

15. Barnett DW, Garrison EK, Quinlan AR, Strömberg MP, Marth GT. BamTools: a C++ API and toolkit for analyzing and managing BAM files. Bioinformatics. 2011; 27: 16912. https://doi.org/10.1093/bioinformatics/btr174.

16. Anders S, Pyl PT, Huber W. HTSeq--a Python framework to work with high-throughput sequencing data. Bioinformatics. 2015; 31: 166-9. https://doi.org/10.1093/ bioinformatics/btu638.

17. Deer EL, et al. Phenotype and Genotype of Pancreatic Cancer Cell Lines. Pancreas. 2010; 39: 425-435. https:// doi.org/10.1097/MPA.0b013e3181c15963.

18. Fryer RA, Barlett B, Galustian C, Dalgleish AG. Mechanisms underlying gemcitabine resistance in pancreatic cancer and sensitisation by the iMiD lenalidomide. Anticancer Res. 2011; 31: 3747-56.

19. Gao F, Sun Z, Sun X, Zhang Y, Wang H, Zhong B, Luo J, Zhao X. Ulinastatin exerts synergistic effects with taxotere and inhibits invasion and metastasis of breast cancer by blocking angiogenesis and the epithelialmesenchymal transition. Cancer Biother Radiopharm. 2013; 28: 218-25. https://doi.org/10.1089/cbr.2011.1122.

20. Deer EL, González-Hernández J, Coursen JD, Shea JE, Ngatia J, Scaife CL, Firpo MA, Mulvihill SJ. Phenotype and genotype of pancreatic cancer cell lines. Pancreas. 2010. 39: 425-35. https://doi.org/10.1097/MPA.0b013e3181c15963.

21. Daemen A, Peterson D, Sahu N, McCord R, Du X, Liu B, Kowanetz K, Hong R, Moffat J, Gao M, Boudreau A, Mroue R, Corson L, O'Brien T, Qing J, Sampath D, Merchant M, Yauch R, Manning G, Settleman J, Hatzivassiliou G, Evangelista M. Metabolite profiling stratifies pancreatic ductal adenocarcinomas into subtypes with distinct sensitivities to metabolic inhibitors. Proceedings of the National Academy of Sciences of the United States of America. 2015; 112: E4410-E4417. https:// doi.org/10.1073/pnas.1501605112.

22. Gradiz R, Silva HC, Carvalho L, Botelho MF, MotaPinto A. MIA PaCa-2 and PANC-1-pancreas ductal adenocarcinoma cell lines with neuroendocrine differentiation and somatostatin receptors. Sci Rep. 2016; 6. https://doi.org/10.1038/srep21648.

23. Kunnumakkara AB, Guha S, Krishnan S, Diagaradjane P, Gelovani J, Aggarwal BB. Curcumin potentiates antitumor activity of gemcitabine in an orthotopic model of pancreatic cancer through suppression of proliferation, angiogenesis, and inhibition of nuclear factor-kappaBregulated gene products. Cancer Res. 2007; 67: 3853-61. https://doi.org/10.1158/0008-5472.CAN-06-4257.

24. Harikumar KB, Kunnumakkara AB, Sethi G, Diagaradjane P, Anand P, Pandey MK, Gelovani J, Krishnan S, Guha $\mathrm{S}$, Aggarwal BB. Resveratrol, a multitargeted agent, can enhance antitumor activity of gemcitabine in vitro and in orthotopic mouse model of human pancreatic cancer. International journal of cancer. Journal international du 
cancer. 2010; 127: 257-268. https://doi.org/10.1002/ ijc. 25041 .

25. Park B, Prasad S, Yadav V, Sung B, Aggarwal BB. Boswellic acid suppresses growth and metastasis of human pancreatic tumors in an orthotopic nude mouse model through modulation of multiple targets. PLoS One. 2011; 6: e26943. https://doi.org/10.1371/journal.pone.0026943.

26. Arora S, Bhardwaj A, Singh S, Srivastava SK, McClellan S, Nirodi CS, Piazza GA, Grizzle WE, Owen LB, Singh AP. An undesired effect of chemotherapy: gemcitabine promotes pancreatic cancer cell invasiveness through reactive oxygen species-dependent, nuclear factor kappaBand hypoxia-inducible factor 1alpha-mediated up-regulation of CXCR4. J Biol Chem. 2013; 288: 21197-207. https://doi. org/10.1074/jbc.M113.484576.

27. Daemen A, Peterson D, Sahu N, McCord R, Du X, Liu B, Kowanetz K, Hong R, Moffat J, Gao M, Boudreau A, Mroue R, Corson L, et al. Metabolite profiling stratifies pancreatic ductal adenocarcinomas into subtypes with distinct sensitivities to metabolic inhibitors. Proc Natl Acad Sci U S A. 2015; 112: E4410-7. https://doi.org/10.1073/ pnas. 1501605112.

28. Collisson EA, Sadanandam A, Olson P, Gibb WJ, Truitt M, Gu S, Cooc J, Weinkle J, Kim GE, Jakkula L, Feiler HS, Ko AH, Olshen AB, Danenberg KL, Tempero MA, Spellman PT, Hanahan D, Gray JW. Subtypes of pancreatic ductal adenocarcinoma and their differing responses to therapy. Nat Med. 2011; 17: 500-3. https://doi.org/10.1038/nm.2344.

29. Conroy T, Desseigne F, Ychou M, Bouche O, Guimbaud R, Becouarn Y, Adenis A, Raoul JL, Gourgou-Bourgade S, de la Fouchardiere C, Bennouna J, Bachet JB, KhemissaAkouz F, et al. FOLFIRINOX versus gemcitabine for metastatic pancreatic cancer. N Engl J Med. 2011; 364: 1817-25. https://doi.org/10.1056/NEJMoa1011923.

30. Dvorakova K, Induction of oxidative stress and apoptosis in myeloma cells by the aziridine-containing agent imexon. Biochem. Pharmacol. 2000; 60: 749-758. https://doi. org/10.1016/S0006-2952(00)00380-4.

31. Engel RH, Evens AM. Oxidative stress and apoptosis: a new treatment paradigm in cancer. Front. Biosci. 2006; 11:300-312. https://doi.org/10.2741/1798.

32. Donadelli M, Dando I, Zaniboni T, Costanzo C, Dalla Pozza E, Scupoli MT, Scarpa A, Zappavigna S, Marra M, Abbruzzese A, Bifulco M, Caraglia M, Palmieri M. Gemcitabine/cannabinoid combination triggers autophagy in pancreatic cancer cells through a ROSmediated mechanism. Cell Death Dis. 2011; 2. https://doi. org/10.1038/cddis.2011.36.
33. Ju HQ, Gocho T, Aguilar M, Wu M, Zhuang ZN, Fu J, Yanaga K, Huang P, Chiao PJ. Mechanisms of Overcoming Intrinsic Resistance to Gemcitabine in Pancreatic Ductal Adenocarcinoma through the Redox Modulation. Mol Cancer Ther. 2015; 14: 788-798. https:// doi.org/10.1158/1535-7163.MCT-14-0420.

34. Wang $Y$, Wu X, Zhou Y, Jiang H, Pan S, Sun B. Piperlongumine Suppresses Growth and Sensitizes Pancreatic Tumors to Gemcitabine in a Xenograft Mouse Model by Modulating the NF-kappa B Pathway. Cancer Prev Res (Phila). 2016; 9: 234-44. https://doi. org/10.1158/1940-6207.CAPR-15-0306.

35. Raj L, Ide T, Gurkar AU, Foley M, Schenone M, Li X, Tolliday NJ, Golub TR, Carr SA, Shamji AF, Stern AM, Mandinova A, Schreiber SL, Lee SW. Corrigendum: Selective killing of cancer cells by a small molecule targeting the stress response to ROS. Nature. 2015; 526: 596.

36. Duan C, Zhang B, Deng C, Cao Y, Zhou F, Wu L, Chen M, Shen S, Xu G, Zhang S, Duan G, Yan H, Zou X. Piperlongumine induces gastric cancer cell apoptosis and $\mathrm{G} 2 / \mathrm{M}$ cell cycle arrest both in vitro and in vivo. Tumour Biol. 2016; 37: 10793-804. https://doi.org/10.1007/ s13277-016-4792-9.

37. Zheng J, Son DJ, Gu SM, Woo JR, Ham YW, Lee HP, Kim WJ, Jung JK, Hong JT. Piperlongumine inhibits lung tumor growth via inhibition of nuclear factor kappa B signaling pathway. Sci Rep. 2016; 6: 26357. https://doi.org/10.1038/ srep26357.

38. Basak D, Punganuru SR, Srivenugopal KS. Piperlongumine exerts cytotoxic effects against cancer cells with mutant p53 proteins at least in part by restoring the biological functions of the tumor suppressor. Int J Oncol. 2016; 48: 1426-1436. https://doi.org/10.3892/ijo.2016.3372.

39. Randhawa H, Kibble K, Zeng H, Moyer MP, Reindl KM. Activation of ERK signaling and induction of colon cancer cell death by piperlongumine. Toxicology in Vitro. 2013; 27: 1626-33. https://doi.org/10.1016/j.tiv.2013.04.006.

40. Lee HN, Jin HO, Park JA, Kim JH, Kim JY, Kim B, Kim W, Hong SE, Lee YH, Chang YH, Hong SI, Hong YJ, Park IC, Surh YJ, Lee JK. Heme Oxygenase-1 Determines the Differential Response of Breast Cancer and Normal Cells to Piperlongumine. Mol Cells. 2015; 38: 327-335. https:// doi.org/10.14348/molcells.2015.2235.

41. Roh, JL, Kim EH, Park JY, Kim JW, Kwon M, Lee BH. Piperlongumine selectively kills cancer cells and increases cisplatin antitumor activity in head and neck cancer. Oncotarget. 2014; 5: 9227-9238. https://doi.org/10.18632/ oncotarget. 2402 . 